\title{
ZNAČAJ IN FUNKCIJE POLITIČNIH MEJA V EVROPI
}

Ključne besede: politična meja, Evropa, evropske integracije, politična geografija

\section{Uvod}

»Meje so padle!« je med najpogosteje ponavljanimi političnimi zablodami sodobne združene Evrope. Popularnost tega slogana je po eni strani odraz vznesenosti, ki se sprošča ob velikih spremembah na starem kontinentu. $V$ procesih evropske integracije se države spreminjajo iz konkurenčnih sosedov in nasprotnikov v (vsaj načeloma) harmonično zvezo na podlagi prostovoljnosti, solidarnosti, vzajemnosti in skupnih koristi. Po drugi strani je priljubljenost slogana o "Evropi brez meja « dokaz nepoznavanja realnosti evropskega političnega zemljevida in procesov, ki ga oblikujejo, ter sil, ki ta prostor formalno in funkcionalno obvladujejo. Je torej posledica parcialnega gledanja Evropejca, ki doživlja svet okrog sebe predvsem izkustveno: zanj je meja vidna, občutena oziroma doživeta pregraja. Že sam izraz »prostor « predvideva njegovo omejenost v horizontalni in vertikalni smeri. Z omejenostjo dobiva prostor bistvene kvalitete. Glede na mejo lahko določimo središče, obrobje ter različna območja, ki se med seboj močno razlikujejo. Politična meja je v tem primeru funkcionalna linija, ki ima vlogo ovire. Ker je organizacija življenja v obmejni pokrajini prilagojena meji, imajo obmejna območja v izgledu, sestavi in funkcijah vrsto posebnosti.

Političnih meja ne moremo razumeti brez poznavanja državne organizacije. Ves čas obstoja držav, od zgodnjeantičnih državnih tvorb prek srednjeveških fevdalnih ozemelj do modernih nacionalnih držav evropskega 
tipa oziroma teritorialnih držav »novega sveta«, je bilo oblikovanje, vzdrževanje, nadziranje in statusno spreminjanje meja dejansko v funkciji državotvornih procesov. Meje so se torej v vsej človeški zgodovini spreminjale tako, kot so se razvijale države: nastajale so in izginjale ter spreminjale svoje lastnosti. Helsinška konferenca o varnosti in sodelovanju v Evropi iz leta 1974 je naredila radikalen rez: politične meje se ne smejo spreminjati, vsa bilateralna vprašanja naj se rešijo z notranjo teritorialno reorganizacijo in različnimi oblikami varovanja narodnih / etničnih manjšin ter $\mathrm{z}$ drugimi postopki. Ta odločitev je postala skoraj sinonim evropske stabilnosti. Vendar zgodovinska izkušnja zanika tezo o nespremenljivosti političnih meja. Že pri kopenskem razmejevanju je tudi po letu 1974 prišlo do nekaj kompromisnih rešitev in korekcij mejne črte; največ zaradi regulacije mejnih vodotokov. Pri tem ne smemo pozabiti na pomorsko razmejevanje, ki je prav od 1970 dalje vsaj v Evropi doživelo svoje največji razmah (Taylor, 1987, 155).

Meje kot politične in pravne linije ostajajo v Evropi velik in trajen izziv. $\mathrm{V}$ prispevku so podane temeljne značilnosti oblikovanja meja in njihovih današnjih funkcij. Zaradi omejenega prostora se avtor osredotoča predvsem na politično-geografsko analizo proučevanja pojava političnih meja in njihovih prostorskih in družbenih posledic. Razprava naj bi vzpodbudila kritično razmišljanje o mejah kot prostorski, politični in družbeni kategoriji evropske stvarnosti.

\section{O značaju političnih meja}

Kaj so (politične) meje? $\mathrm{Z}$ današnje perspektive je to črta na zemljevidu oziroma na različne načine označena linija v pokrajini, ki razmejuje dve politični enoti. Potek mejne črte je rezultat pravnega in političnega sporazuma dveh ali tudi več držav. Današnje politične meje so rezultat zgodovinskih procesov in s tem zgodovinska dediščina. Žal se časovno razsežnost meja rado zanemarja celo v politični in diplomatski praksi in šele meddržavni mejni spori vzpodbudijo odkrivanje prezrte preteklosti. 
Politične meje imajo ločevalni in povezovalni značaj. Medtem ko je prvi logičen in očiten, je drugi prikrit, a zato nič manj pomemben. Ker je bil prvotni namen vzpostavitve meje določitev »našega « ozemlja, je bila to črta dosega državne oblasti in obenem črta zamejitve "naših « interesov. Ločevalnost je tedaj odločno prevladovala. Zato so meje določali - če se je le dalo - na robovih naravnogeografskih enot, kot so na primer grebeni gora in hribovij ter na bregovih rek in jezer. Od tod izvirajo teze, da so to »naravne « meje. $Z$ razvojem vojaške tehnologije in tudi napredkom prometne infrastrukture je postal ločevalni značaj teh meja zelo neprepričljiv. Fizična - geografska ovira torej ni zagotavljala niti jasne razmejitve (delimitacije), še manj pa je zagotavljala varnost. Zato je bilo označevanje in utrjevanje meje značilno že za antiko. Najstarejše civilizacije, ki so oblikovale državne organizacije ob velikih vodotokih Nilu, Evfratu in Tigrisu ter Indu, za zamejitev svoje državnosti niso potrebovale posebnih označitev. Omejevali so jih široki pasovi odprtega, nenaseljenega puščavskega sveta. Ker teh ozemelj niso šteli za koristna, so jih le vojaško nadzirali in branili, niso pa jih natančno razmejevali. Rimski imperij je vzpostavil čvrsto teritorialno organiziranost in za tiste čase zelo učinkovito medsebojno povezanost. Nekatera robna območja, ki so se izkazala za skrajni rob političnega dosega, so izdatno utrdili. Tako so nastali nekateri »limesi« in »zidovi«. Nam najbližji je bil t.i.«langobardski limes« na vzhodnem robu Furlanske nižine, po katerem se je oblikovala tudi kulturna oziroma pozneje narodnostna meja med romansko (furlansko in italijansko) in slovensko tradicionalno naselitvijo. V svetovnem merilu sodi med najveličastnejše primerke te vrste sloviti veliki kitajski zid. Obsežne utrdbe so gradili tudi Rimljani, da bi se varovali pred vdori sosednjih ljudstev (npr. več deset km dolgi Hadrijanov zid).

Ker je bila obramba meje eden od temeljev obstoja politične skupnosti, ki je to omejeno ozemlje obvladovala, so jih izdatno utrjevali tudi pozneje. V srednjem veku je bila zaradi varnostnih razlogov obramba dežel tako pomembna, da so zaradi tega celo mnoga majhna naselja dobila mestne pravice (na primer naša Kostanjevica in Višnja gora). V nizu utrdb protiturške obrambe so posebej oblikovali nekaj mest. Še danes jih lahko prepoznamo po značilnem "zvezdastem " tlorisu starega mestnega jedra, kot ga imata npr. Karlovac in Palmanova. Obramba dežele je bila torej pomemben, $v$ kar številnih primerih celo odločilni lokacijski dejavnik oblikovanja mreže 
mest in njihove urbane izoblikovanosti. Še v 20. stoletju so na mejah gradili obsežne utrdbene sisteme. Tako je znana slovita »Maginotova linija « med Francijo in Nemčijo, pri nas pa »Rupnikova linija«; toda obe sta kaj klavrno vršili svoje obrambno poslanstvo. Po drugi svetovni vojni se je na politično - ideološki razpoki med kapitalističnim »zahodom» in socialističnim "vzhodom« oblikovala dobro nadzorovana mejna linija, ki je pozneje dobila ime »železna zavesa « ${ }^{1}$. Mejno črto so spremenili v mejno cono, saj je obsegala ožji pas strogo varovanega ozemlja, nadzorovanega s stražnimi stolpi, bunkerji, strojničnimi gnezdi, minskimi polji in preoranimi površinami. Taka meja je še danes med severno in Južno Korejo. Razdeljena so bila celo nekatera mesta; gotovo je najbolj znan »berlinski zid ${ }^{2}$ «. Ko je v letih 1989 do 1991 prišlo do razpada socialističnih režimov, je prav "padec berlinskega zidu« simboliziral pot v novo, združeno Evropo. V svetovnem merilu je ločevalnost meja tudi danes še zelo poudarjena. Izraelci so zaradi varnostnih razlogov pričeli graditi desetine $\mathrm{km}$ dolg »varnostni zid«. Tudi ZDA pripravljajo pregrajo, ki bi olajšala nadzor ilegalnega priseljevanja iz sosednje Mehike (Der Fischer Weltalamanch 2008, 245-247). Naposled, a nikakor ne nazadnje so tu tudi politične meje držav članic Evropske unije. Uveljavile so koncept t.i. »schengenskega območja«, znotraj katerega so odpravili policijski in carinski nadzor, poostrili pa so ga na »zunanjih mejah» EU. Nekateri so te meje že pričeli imenovati »schengenski zid«.

\section{Funkcije političnih meja}

Funkcije političnih meja lahko razdelimo na štiri glavne skupine: politične, gospodarske, vojaško-varnostne in kulturne. Ker se med seboj tesno prepletajo, jih je včasih težko ločiti. Ključna politična funkcija meja

1 Izraz »železna zavesa« se je najprej pojavil na slovenski meji med Trstom in Krasom. Pozneje so termin povzeli in se je kot tak uveljavil kot pojem ločenosti evropskega »vzhoda» in »zahoda«. Toda ironično - v zaledju Trsta so zaradi dvostranskih sporazumov že v času trde ločenosti polarizirane Evrope uveljavili (zlasti po sklenitvi t.i. Osimskih sporazumov od 1975 dalje) koncept »odprte meje«.

2 Zid so porušili in je padel dobesedno. Danes stoji le še nekaj delov, ki so jih morali spomeniško zaščititi. 
je omejevanje državnega ozemlja. Do tja sega politična in upravna moč in tam se končajo tudi državljanske pravice državljanov. Politična meja je povezana linija skrajnih točk državnega ozemlja, ki omogoča uveljavljanje drugih funkcij, od varnostnih do kulturnih. S tem se oblikuje tudi identiteta tega omejenega ozemlja. Meja sama ima tudi velik simbolni pomen. Boj za meje, ki ga poznajo praktično vse evropske nacionalne zgodovine, v narodnem spominu zlahka prehaja tenko linijo med realnostjo in nacionalno mitologijo (Delaney, 2005, 73-76).

Meje so bile in so še vedno tudi sorazmerno ostre ekonomske ločnice. Tudi na območjih brez mejnega nadzora bomo lahko zasledili znatne razlike med ozemlji, če so različno upravljana. Nekdanje jugoslovanske republike so se močno razlikovale po gospodarski razvitosti, čeprav meja ni nihče zares nadziral. Zaradi želje po varovanju gospodarskih interesov so meje tudi gospodarsko nadzirali. Na mejnih prehodih potrebujejo poleg varnostnih sil (vojaških in policijskih) sile ter organe ekonomskega nadzora: carino, inšpekcijske službe, finančno policijo in podobno. Že v srednjem veku so različne ozemeljske enote in celo posamezna mesta imela na svojem vhodu mitnico, kjer so se plačevale dajatve in opravljal nadzor. Avtonomnost ozemelj se je merila glede na možnosti gospodarskega in vojaškega nadzora. Tudi nekatere notranje meje so imele značaj carinske pregraje. V času blokovske razdelitve so bile politične meje strogo nadzorovane in je bil pretok blaga, ljudi in storitev posredno omejen. Vse to je poudarjalo pomen pretežno v državne okvire zaprtih gospodarstev. Vendar je glavnina razvitih zahodnoevropskih držav, ZDA ter Japonska že v petdesetih letih 20. stoletja pričela pospešeno iskati možnosti mednarodne izmenjave in povezovanja. V Evropi so ustanovili Skupnost za premog in jeklo, ki je s poznejšim razvojem postala jedro evropskih integracij. Pretočnost in prehodnost političnih meja je hitro postal ključni indikator in obenem motor gospodarskega razvoja. S povečanim čezmejnim prometom se je močno povečeval tudi gospodarski pomen meja. V obmejni prostor se je zaradi obsežnih postopkov carinskega in sanitarnega nadzora selila vrsta služb, različnih storitev in dejavnosti, ki so posredno živele od mednarodnega prometa. Vse to je območjem neposredno ob velikih mejnih prehodih dajalo vrsto prednosti. Oblikovale so se svojevrstne obmejne gospodarske cone, ki so bile donosen vir dohodkov lokalnega gospodarstva. Dohodki od čezmejnega prometa so 
postali pomembna gospodarska kategorija tudi na državni ravni. Poseben pomen so imele prostocarinske cone. S poglabljanjem integracijskih procesov so jih pričeli na notranjih mejah EU odpravljati. Tako opremljene meje, ki so se ob točkah prestopa (mejnih prehodih) spremenile v nekoliko širše mejne cone, so ob izraženi ločevalnosti (od katere izhaja glavnina ekonomskih profitov) postale obenem tudi povezovališča. Obe strani meje sta pričeli sodelovati in sinhronizirati različne dejavnosti. Uspešnost ene strani meje je bila privlačni element tudi za drugo stran.

Kot skrajna zunanja črta državnega ozemlja je mejna linija vedno imela tudi izpostavljen varnostni pomen. Kot omenjeno, so jih zaradi tega izdatno označevali in utrjevali, v nekaterih primerih pa uredili cele obrambne sisteme. Vojaški in policijski nadzor se po načinu delovanja precej razlikujeta. Medtem ko je vojaški nadzor namenjen obrambi pred organiziranimi nasprotnimi silami, je policijski v prvi vrsti namenjen varovanju pred individualnimi prehodi in tudi prehodi kriminalnih skupin. Še posebej je pomembno odkrivanje potencialno nevarnih skupin, kot so na primer verige organiziranega kriminala, ki vnašajo droge, orožje ali pa tihotapijo ljudi. Poleg nadzora neposredno na mejni črti (mejnih prehodih) so praviloma nadzirali širšo mejno cono, saj so omenjene skupine rade ubirale druge ilegalne kanale. Tudi varnostni nadzor je terjal razmeroma obsežno mejno infrastrukturo. Poleg vojaških postojank in različnih utrdbenih sistemov so morali postaviti tudi območja za začasno ali celo stalno pridržanje zajetih ljudi. V zadnjih dveh desetletjih so nekatere meje že varovane tudi elektronsko ali pa celo postavili cele pregraje (različne ovire, ograde in zidovi).

Kulturni značaj in pomen (funkcija) meje ima v kontekstu proučevanja mejnosti posebno mesto. Kulturne in politične meje se pogosto ne pokrivajo in neujemanja so pogosto predstavljala območja sporov v odnosih med državami. V procesu razmejevanja zlasti srednje- in vzhodnoevopskih nacionalnih držav je bil t.i. »etnični« kriterij med poglavitnimi. Toda praksa pozna izjemna odstopanja. Očitno so upoštevali tudi druge, še posebej sklop t.i. "zgodovinskih" dejstev in drugih okoliščin. Ocene etničnih situacij ali celo popisne podatke so pri interpretaciji pogosto prikrojevali merilom lastnih (nacionalnih) koristi. Ne glede na to pa moremo ugotoviti, da je veliko evropskih meja "antropogenih«, da so se torej - kljub velikim kompromisom na ta merila vendarle precej ozirali. Oblikovana politična 
meja je po določenem času pričela bistveno vplivati na podobo pokrajine in ne nazadnje tudi na prebivalstvene strukture. Etnične manjšine so sicer (večidel) dobile pravna in politična jamstva varovanja in nemotenega kulturnega razvoja, vendar so jih samodejni mehanizmi asimilacije in $\mathrm{v}$ večini primerov tudi prikrite ali odkrite protimanjšinske težnje številčno zmanjševale in politično ter kulturno periferizirale. Politične meje so torej ustvarjale nove etnične razmere in s tem tudi preoblikovale kulturno pokrajino. Sledovi starih političnih meja kažejo v nekaterih primerih neverjetno odpornost. Tako je na primer na prostoru današnje srednje Poljske še vidna očitna razlika med nekdanjimi pruskimi, ruskimi in avstrijskimi ozemlji in sicer v zemljiškem katastru, tlorisni zasnovi mest in vasi in celo gozdni sestavi - kljub dokaj homogenim naravnim razmeram. Za dokazovanje tega nam ni treba daleč: razlika med slovensko Štajersko in Prekmurjem na slovenskem vzhodu je dovolj očitna.

\section{Posledice razmejevanja in oblikovanja obmejnih območij}

Politične meje in mejne situacije so skozi zgodovino močno vplivale na izoblikovanost kulturne pokrajine. Te posebnosti so odraz različnih funkcij, ki so jih obmejne cone opravljale skozi daljša obdobja. V preteklosti je izstopala predvsem vojaško-varnostna vloga obmejnih območij. Zaradi tega so širše predele robnega pasu ne le izdatno utrdili $\mathrm{z}$ nizom utrdb in utrjenih mest, temveč bistveno vplivali na prostorsko organizacijo teh območij ter na njihovo prebivalstveno sestavo. Da bi zadržali čim večjo obrambno sposobnost robnih predelov, so oblikovali posebno teritorialno organizacijo teh ozemelj. Tako so na primer ogrske in habsburške dežele na južnih mejah oblikovale protiturški obrambi namenjeno »Vojno krajino«. Prebivalci so bili v zameno za stalno opravljanje vojaške službe v glavnem prosti fevdalnih bremen. Ker je število domačega prebivalstva zaradi nenehnih vojn nazadovalo do kritične mere, so se lotili načrtne kolonizacije. Le stabilna mreža naselij je namreč zagotavljala nadzor in obrambo meje. Naravno revna, a strateško zelo pomembna območja današnjih »krajin« na Hrvaškem so naseljevali s skupinami hrvaških in predvsem srbskih be- 
guncev iz predelov pod vplivom turške države. Vojna krajina je segala tudi v Vojvodino ter današnji romunski Banat. Območja, ki so jih v 18. stoletju iztrgali Otomanskemu imperiju, so bila skoraj povsem izpraznjena in vrh vsega marsikje tudi močvirna. Sledila je zadnja velika agrarna kolonizacija v Evropi: obmejni prostor južnega dela Panonske nižine so pričeli sistematično naseljevati s predstavniki skoraj vseh narodov takratne Habsburške monarhije. Kolonizacijska naselja so se povsem razlikovala od prej znanih tlorisnih zasnov naselij: nastale so velike vasi s pravilnim tlorisom (pravokotno sekajoče se vaške ulice) in za tiste časa zelo velikimi zemljiškimi parcelami in posestmi. Naseljenci so izkopali obsežne osuševalne kanale in kultivirali prej redko naseljeno, pusto pokrajino. Ker so bili kolonisti iz različnih krajev, je tod nastalo eno najbolj etnično in versko mešanih okolij. Velika naselja so bila večidel etnično homogena in so v agrarni dobi zadržala svoje jezikovne in verske značilnosti. Do mešanih zakonov in dinamičnih etničnih procesov je prihajalo predvsem $\mathrm{v}$ mestih. Ti predeli so do danes ostali etnično zelo raznoliki, kljub izdatnim preseljevanjem v 20. stoletju (eksodus predvsem banatskih Nemcev, nekoliko tudi Madžarov). Podobno »krajino« so oblikovali tudi v takratni turški Bosni. Najbolj zahodno bosansko Cazinsko krajino so prav zaradi vojaških potreb naselili z muslimanskim prebivalstvom. To je še danes najbolj islamizirani del Bosne in Hercegovine. Oblikovali so tudi nadpovprečno velike zemljiške posesti in jih skladno s tradicijo zemljiškoposestne razdelitve razdelili na značilne »grude«. Naselja so značilno razpršena, s posamič stoječimi hišami in pripadajočimi objekti. Na zahodnem Madžarskem se je prav tako iz varnostnih razlogov oblikovala Stražna pokrajina - Örseg, ki mu pripadajo tudi porabske vasi s slovenskim prebivalstvom. Prav tako so v nekdanji vzhodni Prusiji (današnja Poljska) oblikovali nize naselij prvenstveno kot prvo obrambno črto; jasno, da je bila tlorisna zasnova povsem podrejena tem ciljem. Na vzhodnem Poljskem so naselili Tatare, ki so marsikdaj prevzeli obrambno funkcijo, se povzpeli v poljski družbi kot neke vrste vojaška kasta, toda v izrazito katoliški državi zadržali islamsko veroizpoved (Koter, Kulesza, 2006, 46-51). Tako imamo v Evropi več nazornih primerov obmejnih pokrajin, ki dolgujejo svoje posebnosti v izoblikovanosti kulturne pokrajine okoliščinam in organizaciji življenja ob meji. 
Obmejnost je v večini evropskih držav navadno negativno vplivala na gospodarski in družbeni razvoj. Posebej ob zaprtih mejah (kot so bile na primer ob t.i. »železni zavesi«) je bilo demografsko nazadovanje ponekod tolikšno, da je bilo upravičeno govoriti o propadanju kulturne pokrajine. Robna območja držav so bila praviloma tudi trajno periferna. Zaradi vojaško-varnostnih razlogov so negativne gospodarske in demografske trende celo pospeševali, verjetno v želji po "praznem « obmejnem pasu, da bi ga potem lažje nadzirali s sodobno tehniko in tehnologijo. Če so bila obmejna območja obenem tudi poselitvena jedra manjšinskega prebivalstva, so neredko imeli še dodaten motiv za zmanjševanje poselitvene privlačnosti. Tako so madžarske oblasti v petdesetih letih razselile del Porabskih Slovencev, kasneje pa obmejni predel Porabja razglasile za narodni park. To je danes pretežno gozdnata pokrajina, ki domačemu prebivalstvu pušča zelo skromne preživetvene možnosti. V Bolgariji so razselili pripadnike turške manjšine, naseljene $\mathrm{v}$ obmejni pokrajini Strandži razselili in tam uredili državna posestva. Danes je ta pokrajina demografsko skoraj prazna. Na Hrvaškem so nekdanje krajine po vojaški operaciji »Nevihta« leta 1995 ostale skoraj nenaseljene. Toda to večinoma ni prineslo strateških prednosti. Nasprotno! Demografsko izpraznjena obmejna območja predstavljajo »mehki trebuh« vsake države.

Ob zaprtih mejah je bila periferizacija torej poglavitni proces, ki je vodil k slabitvi prostorskih struktur obmejnih območij. Nasprotno so se ob odprtih mejah razvile različne oblike čezmejnega sodelovanja. Razlike v gospodarski usmerjenosti so vzpodbujale izmenjavo. Na prometnih mejnih prehodih so se kopičile različne storitvene dejavnosti. Tako se je na mejah med Beneluksom, Francijo in Nemčijo že v sedemdesetih letih 20. stoletja pojavila potreba po oblikovanju gospodarskih con neposredno ob meji. $\mathrm{Na}$ tedanji slovensko-italijanski meji se je po sklenitvi Osimskih sporazumov leta 1975 pričela živahna čezmejna izmenjava ne le dobrin, temveč tudi tehnologije in trženja (Klemenčič, 1987, 69-75). Ker je bila na italijanski strani meje številčna in dobro organizirana slovenska manjšina, je bil pretok informacij še hitrejši in sodelovanje obsežnejše (Bufon, 1995). Podobne izkušnje lahko najdemo tudi na primeru Južne Tirolske v Italiji, ki jo naseljuje številčna, dobro organizirana in tudi gospodarsko močna nemška 
manjšina (Bufon, 2006). Meja je torej generirala vrsto gospodarskih dejavnosti; bila je torej bolj stičišče kot ločnica.

\section{Teorija in praksa oblikovanja evropskih meja}

Pogled na evropski politični zemljevid je - še posebej v luči teorije in prakse mednarodnega razmejevanja - precej presenetljiv. Danes je pri tvorbi meja v ospredju sklicevanje na "pravno-politične« vidike. Pri tem se državne politike pogosto sklicujejo na t.i. »zgodovinske« meje: pravno upravičljivo je torej tisto, kar v neki obliki že obstaja ali pa je zanesljivo (dokazljivo!) obstajalo v preteklosti. Kljub statičnosti tega kriterija je zgodovinska utemeljenost političnih meja bila in je še sedaj v Evropi med najpomembnejšimi premisami razmejevalnega odločanja. Zlasti zahodnoevropske države imajo svoje politično-teritorialne okvire naslonjene na razmeroma stare politične meje. Večinoma imajo izvor v mejah srednjeveških držav. Meja med Francijo in Španijo poteka po gorski verigi Pirenejev, ki je predstavljala jasno ločnico navzven; politična meja se ji je prilagodila. Podobne starosti je tudi meja med Španijo in Portugalsko, čeprav se ne naslanja na naravne pregraje. Na Iberskem polotoku so se meje oblikovale v glavnem že v 13. stoletju, potem ko je španska »reconquista « uspešno izrinila Arabce. Nekoliko mlajše so meje na območju Beneluksa in južne Francije ter zahodnega dela alpskega loka. Tudi v Skandinaviji so meje oblikovane glede na razmeroma staro dediščino prejšnjih administrativnih enot. Le vzhodne finske meje so se oblikovale šele v 20. stoletju. Srednja, Vzhodna in Jugovzhodna Evropa je doživljala precej drugačno zgodovinsko usodo. Velike večnarodne države (habsburška, otomanska, ruska) niso zdržale silnega pritiska narodov, ki so želeli oblikovati svoje nacionalne države; ta proces se še ni povsem zaključil. Povezovanje »nacionalnih « ozemelj je bilo v nasprotju z "zgodovinskimi« pravicami starih imperijev. Do novega razmejevanja je vedno prišlo po predhodnih vojaških spopadih. Zato so bili v razmejevalnih praksah poleg sklicevanja na »zgodovinsko upravičenost« in »kulturna« oziroma »etnična « merila dostikrat upoštevani tudi dosežki na bojnem polju. Nastale meje so bile torej rezultat zelo raznolikih dejavnikov. S tem je poudarjena tudi individualnost političnih meja. Vsak sektor meje ima torej 
svoj »zgodovinski spomin«, akumulirano zgodovinsko dediščino torej, ki jo je dobro poznati, tudi če na diplomatski ravni načeloma zavračamo kakršnokoli razpravo o spremembah političnih meja. Evropejci imamo torej bogato dediščino političnega sprenevedanja okrog vedno kočljivega vprašanja razvoja političnih meja. Tako so vsi narodi rajnke habsburške monarhije $\mathrm{v}$ fazi razkroja črno-žoltega cesarstva po prvi svetovni vojni prisegali na pravičnost »etničnih « meja. Skladno z ponujeno prakso Wilsonovega načela o samoodločbi je bilo izvedenih tudi nekaj plebiscitarnih odločitev. Toda nove države so bile vse večnarodne. V mirnem obdobju dvajsetih in tridesetih let 20. stoletja so skušali manjšine na lastnih ozemljih čimprej asimilirati (kar je pomenilo oster boj proti številnim in številčnim manjšinam), med drugo svetovno vojno in po njej pa doseči "pravične« meje. Po vojni so Nemčijo razdelili in potisnili njene vzhodne meje za dobrih $200 \mathrm{~km}$ proti zahodu ter preselili nad 12 milijonov Nemcev - vse seveda $\mathrm{z}$ namenom doseči stabilen in varen politični razvoj. Ko so v petdesetih letih prejšnjega stoletja dosegli obnovitev italijanske in avstrijske države, je za nekaj desetletij zavladal mir in stabilnost, čeprav v senci ostre politične, ideološke, vojaške, kulturne in gospodarske polarizacije (Bufon, 2007, 261-272). Evropa se je dejansko razvijala dvotirno: socialistični (vzhodni) in kapitalistični (zahodni) del sta imela povsem ločeni paradigmi razvoja. Ko se je proces dekolonizacije po letu 1962 večinoma končal, se je zdelo, da je napočil čas svetovne stabilnosti. Leta 1974 je Helsinška konferenca o varnosti in sodelovanju v Evropi opredelila pragmatično izhodišče: politične meje (Evrope, a tudi sveta!) naj se ne spreminjajo več, notranje odnose naj urejajo z reorganizacijo upravljanja državnih ozemelj. Manjšinska in mejna vprašanja naj države rešijo $\mathrm{z}$ dvostranskimi sporazumi in sicer tako, da bodo zagotovili nemoten razvoj manjšin ter ohranjanje njihove narodne identitete. Obenem se je v zahodni polovici Evrope pričel obširen proces sprva predvsem gospodarskega, pozneje pa vse bolj tudi političnega povezovanja. Stari kontinent je zajel močan tok integracijskih procesov, dokler se ni ob svitu tretjega tisočletja znašel večidel združen v Evropski uniji, na evropskih tleh nesporno največji politično-teritorialni tvorbi vseh časov.

$\mathrm{V}$ času prevlade evrointegracijskih procesov bi površen opazovalec sodil, da so politična razmejevanja bolj ali manj stvar preteklosti. Toda prav $\mathrm{v}$ času, ko je glavnina držav starega kontinenta pričela naglo preobrazbo $\mathrm{v}$ 
Evropsko unijo, je na vzhodu in jugovzhodu Evrope nastala vrsta novih držav. Večinoma je šlo za osamosvojitev že obstoječih političnih entitet - republik nekdanje Sovjetske zveze, Čehoslovaške in Jugoslavije. Medtem ko je razdružitev Češke in Slovaške leta 1993 potekala sporazumno in brez posebnih zapletov, je imelo nadzorovano razdruževanje Sovjetske zveze precej več težav. Vneli so se predvsem "notranji« spopadi in upori ter razglasitve posameznih teritorijev za samostojne države ( $\mathrm{O}^{\prime}$ Laughlin, Kolossov, 1989). V Moldaviji sta tako nastali Pridnestrska republika in Gagauzija (v okviru Moldavije), neodvisnost je razglasila Čečenija (v okviru Rusije), Gorski Karabah (avtonomno ozemlje v Azerbajdžanu), Abhazija, Adžarija ter Južna Osetija (v Gruziji), že pred tem je samostojnost pod turško taktirko razglasila Turška republika severni Ciper. Nekdanjo Jugoslavijo je zajel val medetničnih vojn, ki je na koncu sicer ohranil nekdanje republike v »starih « političnih okvirih, toda obenem je ustvaril tudi nove notranje delitve ozemelj. Vsiljene rešitve so oblikovale "postdaytonsko« Bosno in Hercegovino (1995) in Kosovo (1999) pod nadzorom mednarodnih sil (Zupančič, 2007). Februarja 2008 je Kosovo razglasilo samostojnost. Ko je nekdanja južnosrbska avtonomna pokrajina pričela dobivati mednarodno priznanje, je ušel duh nespremenljivosti evropskih meja iz steklenice. Sledila je močna mednarodna polarizacija o osamosvajanju teritorijev in s tem povezano vprašanje statusa in funkcij političnih meja.

\section{Epilog: Evropa brez meja?}

Po tem skopem pregledu je seveda jasno, da so politične meje dinamičen element $\mathrm{v}$ pokrajini že same po sebi. Spreminja se potek njihove črte, še bolj pa različne funkcije. $\mathrm{V}$ duhu evrointegracijskih procesov naj bi meje-ločnice vse bolj postajale meje-povezovališča. S tem bi postopoma premagali breme preteklih ločevanj in perifernost obmejnih območij. Notranje evropske meje naj bi bile torej politično stabilne črte, ki bi omogočale dinamičen čezmejni pretok in vrsto interakcij med državami. Vendar ta koncept na starem kontinentu očitno ni edini; zlasti na Balkanskem polotoku lahko pričakujemo nadaljnje oblikovanja meja v smislu vzpostavljanja

državnega roba (torej meje kot ločnice). Evropska diplomacija je pri tem 
vprašanju razdvojena med pragmatizmom posameznih članic in načeli skupnosti (EU), ki bi jih najraje spoštovali do največje tolerance političnega pragmatizma članic.

Toda vrnimo se k osnovnemu vprašanju: kako je razmejena Evropa danes? Politične meje v Evropi obstajajo in bodo obstajale tudi v prihodnje. Evropa brez meja je utopija. Glavna skrb združene Evrope bi morala biti namenjena odpravljanju ločevalnosti političnih meja in zmanjševanju perifernosti obmejnih območij. Po drugi strani pa bo potrebno določiti tudi skrajni teritorialni obseg Evrope (več v Rogelj, 2006, 181-189). Prav stabilnost in torej tudi jasna opredeljenost političnih meja lahko zagotavlja dinamiko integracijskih procesov. Vse to pa narekuje oblikovanje premišljene evropske geopolitike, ki bo znala preseči parcialne interese članic in namesto situacijskega prilagajanja (pragmatizma) uveljaviti vsaj na evropskih tleh »evropski« red. Razreševanje mednarodnih konfliktov namreč ne bo mogoče brez resnejšega poseganja $\mathrm{v}$ resnejšo teritorialno rekonstrukcijo države ali celo spreminjanje zunanjih političnih meja (Zupančič, 2006, 161-166) Tako bo tudi enostavneje - a nikakor ne brez problemov - morda uspela reševati zapletene probleme vznikanja novih političnih enot in njihovih odnosov s sosedstvom.

\section{LITERATURA}

Bufon M., Prostor, meje, ljudje. Trst - Ljubljana, 1995.

Bufon M., Proučevanje manjšin in obmejnih območij v zgornjem Jadra$\mathrm{nu}$ - raziskovalni pristopi in problemi v luči politične geografije, Dela 25, 2006, Ljubljana, 25-42.

Bufon M., Osnove politične geografije, 2. izdaja, Koper, 2007.

Delaney D., Territory. A short Introduction, Oxford, 2005.

Der Fischer Weltalamanch, 2008, Frankfurt a. Main, Fischer Verlag. 
Klemenčič V., Državna meja na območju SR Slovenije in obmejna območja kot geografski fenomen, Razprave in gradivo 20, Ljubljana, Inštitut za narodnostna vprašanja, 57-81.

Koter M., Kulesza M., Forms of rural settlements in Poland and their transformation in the course of history, Dela 25, 2006, Ljubljana, 43-60.

O 'Laughlin J., Kolossov V., New borders for new world orders: territorialities at the fin-de siecle, GeoJournal 44, 1989, 259-273.

Rogelj B., Nazaj k Evropi - geopolitični diskurzi o Srednji in Vzhodni Evropi v institucijah, Dela 26, 2006, Ljubljana, 181-203.

Taylor P. G., Political Geography - World Economy, Nation State and Locality, London, 1987.

Zupančič J., Geografski pristopi k proučevanju kriznih območij, Dela 26, 2006, Ljubljana, 161-180.

Zupančič J., Nemirni Balkan, Geografski obzornik, letnik 54, 2007, št. 1, 413. 


\section{THE NATURE AND FUNCTIONS OF EUROPEAN POLITICAL BORDERS}

Keywords: political borders, Europe, European integrations, political geography

\section{Abstract}

The political border limits a state's territory and symbolizes the extent of a state's power and ownership. Borders give integrity to the inner state territory which they enclose (the role of establishing national integrity) and at the same time form an outer boundary segregating the state territory from the surrounding politicial entities (the segregation role). European borders are old and reflect the political history of an old continent. The last major border changes happened after World War II. Over the centuries borders were merely lines separating one territory from another. Such borders were understood as »frontiers «. Forming an effective barrier against enemies was the overriding function of borders. Many borders were fortified and further enhanced by means of various defensive systems. In the second half of the $20^{\text {th }}$ century the character of political borders changed. They became a contact area between countries, nations and cultures. Contemporary European borders reflect the colourful history of an old continent. They are predominantely functional markers: they represent the political and juridical delimitation of territories, they mark economic barriers and show their defensive nature and reveal the extent of cultural contact. As a result of European integration processes, the nature of political borders has changed: instead of division, their integration role is brought to the fore. A united Europe is nevertheless still not a borderless Europe! The borders within the »Schengen-area « have retained their political and administrative functions, it is just that the customs and security checks at the borders have been removed. During the period of European integration, borderlines were stabilized in accordance with the 1974 Helsinki Agreement. But despite this we can still observe ongoing changes to state borders, particularly in areas of conflict such as the Balkan peninsula. It seems after all that the process of demarcation of political borders has not yet come to an end. 